\title{
Social sustainability as a challenge for urban scholars
}

\section{Jenni Cauvain}

Urban sustainability is an increasingly popular term used by scientists and policymakers from all disciplines, increasingly without any reference to the tradition of critical urban studies. It is often observed that the social pillar is missing, if sustainability is understood via the 'three-legged stool' concept encompassing social, economic and environmental dimensions. With a few notable exceptions, there appears to be a lack of interest also within urban scholarship to use the term 'social sustainability' to address this gap, although critical urban scholars are productive in the critique of sustainability as a social and political construct. Drawing on the idea of a politics of knowledge, this paper points to political, institutional and conceptual factors that have limited the purchase of social sustainability in research. These factors are rooted in sustainability being predominantly understood as an environmental concern, and a culture that may marginalise research subscribing to a postpositivist epistemology. This article asks whether the social pillar of sustainability could offer a discursive and symbolic tool for researchers to make the case for a critical urban epistemology in interdisciplinary research environments. 


\section{Introduction}

The positionality of the critical urban scholar has been debated in this journal. It is argued that they lack influence and power on the one hand, although they are uniquely positioned to influence urban development on the other (Schafran 2014; 2016). In his response to Schafran, Madden $(2015,297)$ emphasises the role of critical urban scholars in challenging what he calls 'urbanist techniques ... in the instrumental-rational and technocratic sense' that are central to 'statecraft and other dominant practices' that influence the trajectory of our urban futures. What both accounts acknowledge is a certain place and purpose for a critically constructed urban epistemology, although they disagree on how this should be developed as an intellectual and practical project. Madden (ibid) sums up Schafran's central frustration: "critical urbanists are, for the most part, external to the apparatuses and institutions that dominate and determine the production of urban space across the planet". This paper is also concerned with this peripherality, albeit in a more narrowly defined argument within a dominant research culture surrounding urban sustainability. It relates the critical urban scholar not so much to the empirical object of her study, the city, but with academic peers and the politics of knowledge that affects her influence on the creation and reproduction of knowledge about the urban.

The Schafran-Madden debate is primarily fixed on researchers' external influence and their message, and less so on the environment within which critical urban scholars construct their argument. The so-called STEM subjects (science, technology, engineering and mathematics) following a positivist-deductive logic occupy a hegemonic status reinforced by the institutions and culture of academic research where urban sustainability is imagined largely as a 'technoscientific' challenge, and therefore the purpose of sustainability research is largely to define and 'fix' these problems. Recognising this balance of power, this short contribution advocates the use of social sustainability by critical urban scholars as a 
discursive and symbolic tool in interdisciplinary collaborations where it can serve as a legitimising concept.

The central provocation is about how the dominant discourse on urban sustainability serves to include and exclude certain research methods and philosophies. The Enlightenment philosophers' enduring legacy which appeals to the human kind's desire to 'devise logically or scientifically irrefutable ground rules for the production of all valid knowledge' (Weinberg $2008,14)$ is the mood music that sets the tone for this debate. The resulting epistemological marginalisation, where research relating to a post-positivist paradigm or constructionist philosophy is rendered less relevant, makes the critical urban case harder to advocate in mainstream contexts. A similar point has been raised by Brenner and Schmid (2015) in this journal when they discussed the 'crisis' of urban epistemology in general, and it resonates with the Schafran-Madden debate about the positionality of the urban scholar vis-à-vis urban development on the one hand, and the scholar's relationship with emancipatory politics and critique of 'neoliberalism' on the other. In my own experience, the political nature of critical urbanism is particularly contested in interdisciplinary settings, reaching the core argument around what is social justice and why it should matter for sustainability. The 'missing pillar' metaphor (Davidson 2009; Opp 2016) referring to the absence of social sustainability in research and policy literature on urban sustainability is emblematic of the status quo, and it suggests that such literature is largely silent on the political aspects of urban questions. The under-utilised concept of social sustainability could help critical urban scholars to position their research within mainstream debates on sustainability.

A dominant research culture leading to a narrowly defined epistemological boundary for 'accepted' scientific knowledge can emerge in any discipline. Indeed this has been brought to light within health research. Holmes et al argue: "the evidence-based movement in the health sciences is outrageously exclusionary and dangerously normative with regards to scientific knowledge" $(2006,180)$. A culture of epistemological marginalisation may exist in 
the Anglo-American research tradition that affects many areas of scientific enquiry around humanity's 'grand challenges'. Regarding climate change research, MacGregor (2010) argues that a lack of feminist critique weakens the discipline. MacGregor's point refers to the dominance of one research philosophy over alternative approaches; within climate research there are 'dominant tendencies to see ... science as apolitical and social justice as a luxury that cannot be chosen over survival' (ibid, 124). Parallels can be drawn between both these examples and the epistemological basis of urban knowledge where there has been a surge in neo-positivist 'technoscientific urbanism' which is associated with 'the tools of natural science, mathematics and 'big data" (Brenner and Schmid 2015, 156). This influences the hegemonic research culture and narratives that all urban scholars must contend with. The paradox embedded in this philosophically grounded politics of knowledge is that the motivation behind many of the Enlightenment philosophers was to speak truth to power and engage in socially emancipatory causes (Weinberg 2008, 16), and yet the present-day legacy of their epistemic paradigm may have the opposite effect within the urban sustainability research environment that is the focus of this paper.

This short debate is structured as follows; first I describe how sustainability science became dominated by certain tools and methods, and how this is reflected in perceptions about social sustainability. Next, political-institutional and conceptual factors that limit the purchase of social sustainability are sketched out. These vignettes reach beyond the well-recognised lack of influence that critical urban scholars have on urban development per se, they describe what exits further upstream in the way in which research institutions and culture favour particular narratives and epistemologies to identify and subsequently 'fix' urban sustainability problems. The concluding discussion asks whether social sustainability could be deployed as a discursive tool to create a space for critical urban research, especially in interdisciplinary efforts. 


\section{Social sustainability - the missing pillar or the marginalised pillar?}

The three-pillar notion of sustainability understood via economic, environmental and social dimensions has been popularized since the 1987 Brundtland report Our Common Future; despite a wide range of attempts to quantify and clarify the concepts, they still remain 'slippery' and contested (Davidson 2010, 872). Even in the early days of sustainability science, Basiago (1995) contends that sustainability had been adopted as a kind of "new philosophy', or a 'universal methodology', within diverse policy and research communities, broadly accepting sustainable development as a paradigm without knowing what it means or how to achieve it. In terms of the epistemic-philosophical foundations of sustainability thinking, certain disciplines and epistemic communities emerged as key advocates, and their visions still influence sustainability narratives and methods of research today. These key advocates were natural scientists and economists: 'Many early advocates for sustainability and sustainable development were scientists and economists interested in the use of models to predict sustainable levels of natural resource extraction, economic production and consumption.' (Schlossberg and Zimmerman 2003, 642; see also Cuthill 2010; Imrie and Lees 2014; Dillard et al. 2008; Krueger and Savage 2007; Littig and Griessler 2005; Murphy 2012; Opp 2016; Vallance and Perkins 2010; Vallance et al. 2011). In practice, the continued dominance of modelling methods is demonstrated for example by the globally influential Belmont Challenge that supports interdisciplinary research to implement the United Nation's (UN) sustainable development goals; however, assumptions about model predictions and seamless (singular) knowledge are woven into its policies largely justified by their policy relevance and impact (Lahsen et al. 2015). This is a stark reminder of the appeal of universal 'ground rules' (Weinberg 2008) for the production of knowledge.

In terms of thematic focus, critical urban scholars agree that urban sustainability research remains fixed on environmental issues: 'the emphasis remains on how to align cities and city living with the constraints, possibilities and possible limits of the earth's physical 
environment' (Cook and Swyngedouw 2012, 1960). Those urban scholars who address social sustainability explicitly tend to agree that it is the forgotten pillar (Cauvain 2018; Davidson 2010; Dempsey et al. 2011; Opp 2016). Opp $(2016,2)$ sums up the view from urban literature: 'even with the widespread acknowledgement of the importance of social equity, it is a concept that still remains chaotic, understudied, and even outright neglected in the growing sustainable cities literature'. The neglect is 'huge', according to a UK-based environmental scientist Tim O’Riordan: 'I applaud Magnus Boström and his colleague authors for addressing the still hugely neglected topic of social sustainability in its broad context.' (O'Riordan 2012,1, emphasis added). The broad context referred to here by O'Riordan is one of 'deep social and economic inequalities' (ibid). Indeed social equity is meant to be a founding principle of sustainability (Basiago 1995, 118), as reflected in the UN's development goals, and repeated in 'sustainable cities' literature with an interest in environmental and social justice (Haughton 1999). What is relatively new in this context is that the UN adopted a new sustainable development goal to 'Make cities inclusive, safe, resilient and sustainable' in 2016. Whilst this focus on cities should be welcomed by critical urban scholars, Brenner and Schmid $(2015,155)$ argue that paradoxically, the rising importance of cities under a global empirical gaze has resulted in a 'black-boxing' of more qualitative and constitutive questions about the city. This article asks whether such constitutive questions could be put to mainstream sustainability research consortia by critical urbanists through mobilising the missing pillar of social sustainability?

There are numerous reasons as to why, in the main, this has not been the case thus far. Social sustainability is widely perceived to be more difficult to define and operationalise than the other sustainability pillars. For example, Vallance et al. $(2011,342)$ argue that the concept of social sustainability is in chaos: 'many and varied contributions of social scientists have led to a degree of conceptual chaos and ... this compromises the term's utility'. Other commentators accept that there is no overall definition because of 'diverging study perspectives and discipline-specific criteria' (Colantonio 2010, 79). This claim about 
conceptual chaos is of course justified looking at the diverse application of social sustainability in literature. There are a few excellent papers that discuss social sustainability research, such as Vallance and colleagues (2011) and Davidson (2009; 2010) from within urban studies. However, at heart this argument implies that environmental and economic dimensions of sustainability are not in chaos, or indeed that there is a consensus around them, which is not a true reflection of those debates (see, eg Dobson 1998; or more recently Pearce et al. 2015 on 'scientific consensus' in climate change communication). It has been argued that the environmental sustainability narrative feels inherently more cohesive around the core values of environmental protection and resource scarcity while social sustainability is an 'empty concept' that needs to be populated (Davidson 2010). However, ultimately, all sustainability pillars can be equally contested. Could there be underlying reasons for why social sustainability appears less convincing? Firstly, there is a much larger body of work on biophysical aspects of sustainability so the field is simply more mature, but importantly, the methods and traditions of natural science carry more weight in public perception, as discussed below.

\section{Political, institutional and conceptual challenges}

The first of the challenges identified in this paper can be described as political and institutional. Within research institutions, the lack of priority given to arts, humanities and social sciences in the current political and economic settlement on research funding is the most visible part of this. Senior social science figures in the UK have expressed concern over how social sciences are 'sidelined' in research funding and policy influence (the Guardian 2015). In the UK, the current allocation of science and research funding (DBIS 2016) distributes more than 90 per cent of all funds to research councils representing biotechnical, engineering, physical, medical and natural environments. Research that adheres to positivist and deductive methods is overwhelmingly favoured within grant making bodies, and within policy-making there is a strong preference for quantitative and 
economically quantifiable evidence. Within UK research councils, the move towards cutting down on smaller grants and preference given to a smaller number of large grants also discriminates against social science programmes where research budgets tend to be smaller. Therefore, institutionally, there are fewer opportunities for pursuing social sustainability research. Politically, a higher value is placed on natural and physical sciences as well as economics, the latter due to the hegemony of economic discourse in public life in general (Hall, Massey and Rustin 2013). This last point relates to a less visible but equally important social and political phenomenon of how a 'frame' is set for public debates; Hall et al. (ibid) describe how a hegemonic narrative normalises the values of the present (neoliberal) settlement which marginalises debates on the difficult political questions that are confronted by social sustainability research. When research institutions valorise outputs through external impact, grant capture and citations, work that speaks of potential disruptions to the status quo runs a high risk of being considered marginal or mistrusted outside of the narrow audiences who share those same values. The challenge is for critical urban scholars to win trust for ideas that question the assumptions around the hegemonic narrative on sustainability and the established social and political settlement.

The second challenge outlined is conceptual-philosophical. The positivist-deductive philosophy of the natural sciences, in the spirit of the Enlightenment era, is thought to produce 'value-free' facts (Castree et al. 2014). By contrast, socially constructed, interpretive knowledge is dependent upon its context and the interpreter (Turcu 2013). Anything social in sustainability research is perceived to be subject to the vagaries of different political, cultural and normative preferences (Bostrom 2012; Murphy 2012). This leads to the idea that social sustainability is 'particularly difficult to realize and operationalize' (Bostrom 2012). In my own experience of interdisciplinary encounters, social sustainability is challenging to translate into the hegemonic sustainability research environment because the positivist-deductive scientific frame does not readily account for relational and moral 
concepts such as justice and values. Related to this point, the persistent calls for universal, singular knowledge are of course diametrically opposed to the argument about justice. Indeed it has been acknowledged within urban studies that 'the space for justice is highly contested terrain for conflicting social values' (Merrifield and Swyngedouw 1996), this could explain much of the discord in the discussions about social sustainability, and also why debates pertaining to social sustainability do not cross disciplinary boundaries easily. However, so-called neutral scientific facts in the positivist tradition also become loaded with value, but in less obvious ways: 'It is thus important to reveal how science and technology can serve to internalize and reproduce certain values without seeming to' (Castree et al. 2014, 766).Ultimately, it is questionable to single out social sustainability, given the contradictions and surrounding 'impossible sustainability' in its own right (Swyngedouw 2007).

The prevailing sustainability research culture favours natural sciences which are perceived to be more authoritative than contributions emanating from the social science community. This problematic is neatly summed up in Mike Hulme's (2009) book about Why we disagree about climate change. In making this symbolic leap from sustainability to climate change, it is recognised that sustainability debates have become largely coterminous with climate change, although the two are not the same thing. The sustainability narrative reflects this bigger picture of who can speak with authority: 'In the field of climate change, scientists, politicians and journalists are likely to take the views of natural scientists more seriously than those of anthropologists, sociologists, or political scientists, even when the issues are concerned with the behaviour of social systems rather than natural systems' (Steve Rayner, foreword to Mike Hulme's 2009 book). Given the number of senior scientists who argue for a social and relational lens to be applied to questions of sustainability, it is telling of the challenges surrounding social sustainability that its potential as a concept has not been reexamined in this light. 


\section{Should critical urban researchers engage with 'the missing pillar'?}

Why would anyone wish to work with a concept that is labelled chaotic and difficult among their own ranks? Amidst the many known challenges, social sustainability has one particular advantage too. It is a widely recognised 'meta concept'; it can facilitate debate on a broad basis. Of course it can also do the opposite and obfuscate complex matters further. Whether it is helpful or not depends on the context and intended audience, and ultimately, on the will of the potential advocate. Social sustainability could provide a less polarising starting point, compared with the topics it ultimately speaks for, such as justice and inequality. It could also be used to query the objectives and direction of any proposed biophysically focused study. In my own experience, social sustainability has been a legitimising starting point within interdisciplinary settings, making a case for a critical urban perspective.

In theory, the opportunity is there for a greater diversity of scholars to take part in the rising trend of interdisciplinary research being called for by international and national research policies and funding bodies. Critical urban scholars have welcomed this trend (Castree et al. 2014) as a way to redress the balance of the hegemonic interpretations, and a strong case has been made for social scientists in climate change research (Grundmann 2016). However, to challenge the intellectual status quo does not provide for an easy fit within programmes often dominated by what Brenner and Schmid (2015) describe as 'universalising' and 'naturalistic' urban research agenda.

Critical urban scholars have broadly agreed on one thing; the mainstream notion of sustainability is: 'inherently flawed through its technocracism, its foundational view of the nature of nature and disavowal of questions of social (in)equality and (in)justice' (Cook and Swyngedouw $(2012,1961)$. How could urban scholars utilise the missing social pillar to challenge the hegemonic narratives of 'flawed' sustainability? The starting point would be a dialogue about the different philosophical approaches to research, and what these different traditions can bring to the research effort. Other than the challenges of social sustainability, it 
is then also necessary to talk about its strengths. As an antidote to the universalising tendencies of the positivist-deductive frame, constructivist theory has contributed radical and unprecedented epistemological depth and subtlety to understanding the processes through which social problems are defined, remedied, replaced etc. (Weinberg 2009) - a lens that seems particularly useful to apply to the diverse and evolving study of the 'problems' of sustainability. The loose frame of social sustainability allows for a plurality of approaches to be deployed which is also a strength.

Castree et al. $(2014,766)$ identify some 'preconditions for a wider dialogue' in interdisciplinary engagements on global environmental change, these echo some of the central points raised here about social sustainability. Castree et al. (2014) argue that the mainstream scientific community are used to treating the human aspect with a specific style, in other words with one that speaks to their preconceived ontological and epistemic truisms where 'human systems' are best analysed and understood via the same methods and models as 'biophysical systems'. Another precursor relates to social scientists themselves; they represent a multitude of approaches and voices which may not be uniform, and this should be accepted. Therefore, to label social sustainability as (more) chaotic (than other sustainability pillars) is to indirectly demand the diverse community of researchers to speak in unity which is neither possible nor perhaps even desirable. It is not necessary to have a universal definition of social sustainability in order to mobilise the term, but it would help if scholars with shared values and epistemic traditions, such as critical urban scholars, would collectively build a narrative around social sustainability that underpins their own research philosophy. If critical urbanists accept that the bio-physical emphasis on the management of environmental crises serves to preserve the prevailing status quo (Swyngedouw 2009), then the job of the missing social pillar is to re-politicise the research agenda which normalises this consensus. This points towards interdisciplinary engagements on urban sustainability; the challenge for critical urban scholars is to garner validity and recognition for their methods 
and research philosophy in this arena where they are the junior partner. Social sustainability could offer a platform for advancing a critical urban epistemology.

Becoming aware of the dominant research culture gives the urban scholar two options to pursue vis a vis her own research; to put her head above the proverbial parapet, or stay below it. This decision will have consequences for the type of knowledge likely to be produced, how it will be received, and even the career she may pursue as a scholar. The argument has been made that urban scholars broadly fall into two camps when it comes to their position on social sustainability: those subscribing to the Marxist intellectual tradition of demanding a radical, emancipatory and disruptive change to the present social order via political means, and those who find alternative strategies to investigate social sustainability via concepts such as quality of life, social cohesion, or social sustainability as a subordinate question to biophysical enquiry about how the Earth's resources should be shared and preserved for future generations (Davidson 2009). Davidson posits that ultimately any social sustainability topic will always lead to the central question of political will in the context of the city.

This paper attempted to shift the focus from urban development, as debated earlier in this journal, it is broadly accepted that critical urban researchers are peripheral to these processes (Madden 2015). Instead, I draw attention to a politics of knowledge influencing urban scholars further upstream in the research process. The framing of urban sustainability as an environmental issue, and a research culture that valorises positivist and deductive methods have contributed to a neglect of social sustainability as a research topic, and a marginalisation of the values and methods it stands for. If present trends continue, it is likely that urban sustainability expertise and narratives move further and further away from the philosophical foundations of critical urban studies. From this perspective, social sustainability is a largely unexploited opportunity in research contexts where the three-pronged reading of sustainability is an accepted conceptual and symbolic device. 



\section{References}

Basiago, Andrew D. 1995. "Methods of Defining 'Sustainability'." Sustainable Development 3(3): 109-19.

Brenner, Neil and Christian Schmid. 2015. "Towards a New Epistemology of the Urban?" City 19 (2-3): 151-82.

Castree, Noel, William M. Adams, John Barry, Daniel Brockington, Bram Büscher, Esteve Corbera, David Demeritt. 2014. "Changing the Intellectual Climate." Nature Climate Change 4 (9): 763.

Cauvain, Jenni. 2018. "Urban Social Sustainability - A case study of Nottingham, United Kingdom." In The Palgrave Handbook of Sustainability, edited by Robert Brinkmann and Sandra Garren, 241-260. London: Palgrave Macmillan.

Cook, Ian. R, and Erik Swyngedouw. 2012. "Cities, Social Cohesion and the Environment: Towards a Future Research Agenda." Urban Studies 49 (9): 1959-1979.

Cuthill, Michael. 2010. "Strengthening the "social" in sustainable development: Developing a conceptual framework for social sustainability in a rapid urban growth region in Australia." Sustainable Development 18(6): 362-373.

Dobson, Andrew. 1998. Justice and the Environment: Conceptions of Environmental Sustainability and Dimensions of Social Justice. Oxford: Oxford University Press.

Davidson, Mark. 2009. "Social Sustainability: A Potential for Politics?" Local Environment 14 (7): 607-19.

Davidson, Mark. 2010. "Social Sustainability and the City." Geography Compass 4(7): 872880.

Demeritt, David. 2002. "What Is the 'Social Construction of Nature'? A Typology and Sympathetic Critique." Progress in Human Geography 26 (6): 767-90.

Dempsey, Nicola, Glen Bramley, Sinead Power and Caroline Brown. 2011. "The Social Dimension of Sustainable Development: Defining Urban Social Sustainability." Sustainable Development 19(5): 289-300.

Department for Business, Innovation and Skills, DBIS (2016) "The allocation of science and research funding 2016/17-2019/20”. https://www.gov.uk/government/publications/scienceand-research-funding-allocation-2016-to-2020

Dillard, Jesse, Veronica Dujon and Mary C. 2008. Understanding the Social Dimension of Sustainability. New York: Routledge.

Grundmann, Reiner. 2016. "Climate Change as a Wicked Social Problem." Nature Geoscience 9(8): 562.

The Guardian. 2015. "Unloved and sidelined: why are social sciences neglected by politicians?" March 11. http://www.theguardian.com/higher-educationnetwork/2015/mar/11/unloved-and-sidelined-why-are-social-sciences-neglected-bypoliticians

Hall, Stuart, Doreen Massey and Michael Rustin. 2013. "After Neoliberalism: Analysing the Present." Soundings 53: 8-22. 
Holmes, Dave, Stuart J. Murray, Amelie Perron and Genevieve Rail. 2006. "Deconstructing the Evidence-Based Discourse in Health Sciences: Truth, Power and Fascism." International Journal of Evidence-Based Healthcare 4(3): 180-86.

Imrie, Rob and Loretta Lees, eds. 2014. Sustainable London?: The Future of a Global City. Bristol: Policy Press.

Hulme, Mike. 2009. Why We Disagree About Climate Change: Understanding Controversy, Inaction and Opportunity. Cambridge: Cambridge University Press.

Krueger, Rob and David Gibbs, eds. 2007. The Sustainable Development Paradox: Urban Political Economy in the United States and Europe. New York: Guilford Press.

Lahsen, Myanna, Andrew Mathews, Michael R. Dove, Ben Orlove, Rajindra Puri, Jessica Barnes, Pamela McElwee, Frances Moore, Jessica O'Reilly and Karina Yager. 2015. "Strategies for Changing the Intellectual Climate." Nature Climate Change 5: 391.

Littig, Beate and Erich Griessler. 2005. "Social Sustainability: A Catchword between Political Pragmatism and Social Theory." International Journal of Sustainable Development 8(1): 6579.

Madden, David. 2015. "There Is a Politics of Urban Knowledge Because Urban Knowledge Is Political: A Rejoinder to 'Debating Urban Studies in 23 Steps.”' City 19(2-3): 297-302.

MacGregor, Sherilyn. 2009. "A Stranger Silence Still: The Need for Feminist Social Research on Climate Change." The Sociological Review 57: 124-40.

Murphy, Kevin. 2012. "The Social Pillar of Sustainable Development: A Literature Review and Framework for Policy Analysis." Sustainability: Science, Practice \& Policy 8(1): 15-29.

O'Riordan, Tim. 2012 "On social sustainability in a world of limits facing prolonged austerity." Sustainability: Science, Practice and Policy, 8(1): 1-2.

Opp, Susan M. 2016. "The Forgotten Pillar: A Definition for the Measurement of Social Sustainability in American Cities." Local Environment 22(3): 286-305.

Pearce, Warren, Brian Brown, Brigitte Nerlich and Nelya Koteyko. 2015. "Communicating climate change: conduits, content, and consensus." Wiley Interdisciplinary Reviews: Climate Change 6(6): 613-626.

Schafran, Alex. 2014. "Debating Urban Studies in 23 Steps." City 18(3): 321-30.

Schafran, Alex. 2015. "The Future of the Urban Academy." City 19(2-3): 303-5.

Swyngedouw, Erik. 2007. "Impossible "sustainability" and the postpolitical condition." In The sustainable development paradox: urban political economic in the United State and Europe, edited by Rob Krueger and David Gibbs, 13-40. New York: Guilford Press

Turcu, Catalina. 2013. "Re-thinking sustainability indicators: local perspectives of urban sustainability." Journal of Environmental Planning and Management, 56(5): 695-719.

Vallance, Suzanne and Harvey Perkins. 2010. "Is another city possible? Towards an urbanised sustainability." City 14(4): 448-456.

Vallance, Suzanne, Harvey C. Perkins and Jennifer E. Dixon. 2011. "What Is Social Sustainability? A Clarification of Concepts." Geoforum, Themed Issue: Subaltern Geopolitics 42(3): 342-48. 
Weinberg, Darin. 2008. "The Philosophical foundations of constructionist research" In Handbook of constructionist research, edited by James A. Holstein and Jaber F. Gubrium, 13-40. London. The Guildford Press.

Weinberg, Darin. 2009. "On the construction of social problems and social problems theory." The American Sociologist 40: 61-78. 